\title{
The seasonal incidence of bleeding from the upper gastrointestinal tract
}

\author{
M. J. S. LANGMAN
}

From the Department of Gastroenterology, Central Middlesex Hospital, London

EDITORIAL SYNOPSIS The seasonal incidence of bleeding from gastric and duodenal ulcer has been investigated and an increase found in the winter months. This is more pronounced for gastric ulcer. The effect of environmental temperature upon this rhythm has also been investigated but no clear correlation has been found. No seasonal variation has been found for a more limited series of radiologically negative cases.

It has been suggested in the past that symptoms of gastric and duodenal ulceration are prevalent in the winter. In particular, it has been contended that ulcers are more likely to bleed in the winter than in the summer.

Many previous studies have been made but most of these have treated bleeding gastric and duodenal ulceration as a single entity (Christiansen, 1935; Hinton, 1931; Baker, 1947). Previous analyses of the seasonal incidence of gastric ulcer haemorrhage taken alone have been inadequate due to small numbers of cases, and only two investigations, both in the U.S.A. (Boles and Westerman, 1954; Breen and Grace, 1962), have been made of duodenal ulcer bleeding. This paper therefore presents the results of an inquiry into the seasonal incidence of admissions of patients for bleeding gastric and duodenal ulcers to two large general hospitals in London: some figures are also given for the variation in admissions of cases of radiologically negative bleeding to one of them.

\section{METHOD}

At the Central Middlesex Hospital and St. James's Hospital, Balham, two large general hospitals about eight miles apart in London, a special interest has been maintained in the problem of peptic ulceration. At both hospitals records are kept of all admissions for acute upper gastrointestinal haemorrhage and a vigorous diagnostic policy is pursued.

The records of all such patients admitted within the period 1952-61 to either hospital have been examined and from them have been selected all cases with a definite diagnosis of gastric or duodenal ulcer. Radiological, gastroscopic, operative, or post-mortem findings of a chronic ulcer have been considered as acceptable criteria for admission to the groups. Cases with the double diagnosis of gastric and duodenal ulceration have been excluded. At the Central Middlesex Hospital only, all cases where an acute erosion was seen on gastroscopy or the radiograph was normal were put in a further group entitled radiologically negative.

In each case the month of admission has been noted and separate tables of seasonal incidence have been compiled for gastric and duodenal ulceration and for radiologically negative bleeding. The variation between the summer months, April to September, and winter months, October to March, has been compared and evaluated statistically.

The effect of temperature as opposed to season has been investigated on chronic ulcer bleeding only with the aid of data supplied by the Meteorological Office London Weather Centre. This has been done by taking the mean minimum temperature ${ }^{1}$ recorded at Kingsway, central London, for every month in each year of the 10-year period. From the 10 readings for each month the five hotter and five colder months have been separated from January through to December. Thus in January there are 10 readings from 1952 to 1961 and the five months with hotter readings have been compared with the five months with colder readings. In this fashion a table of differential incidence has been drawn up for hot and cold months at the same time of year.

Instances of overlap have sometimes occurred when the same temperature values were recorded in the same month of different years. It has been necessary to allot such months at random to either group so that there are still five monthly periods per group.

\section{RESULTS}

Table I shows the number of admissions for gastric ulcer, duodenal ulcer, and radiologically negative bleeding for the 10 years when separated month by

\footnotetext{
${ }^{1}$ Defined as the mean of the lowest daily temperature readings
} recorded for all the days in the month. 
TABLE I

INCIDENCE OF ADMISSION TO TWO LONDON HOSPITALS FOR HAEMORRHAGE MONTH BY MONTH 1952-61

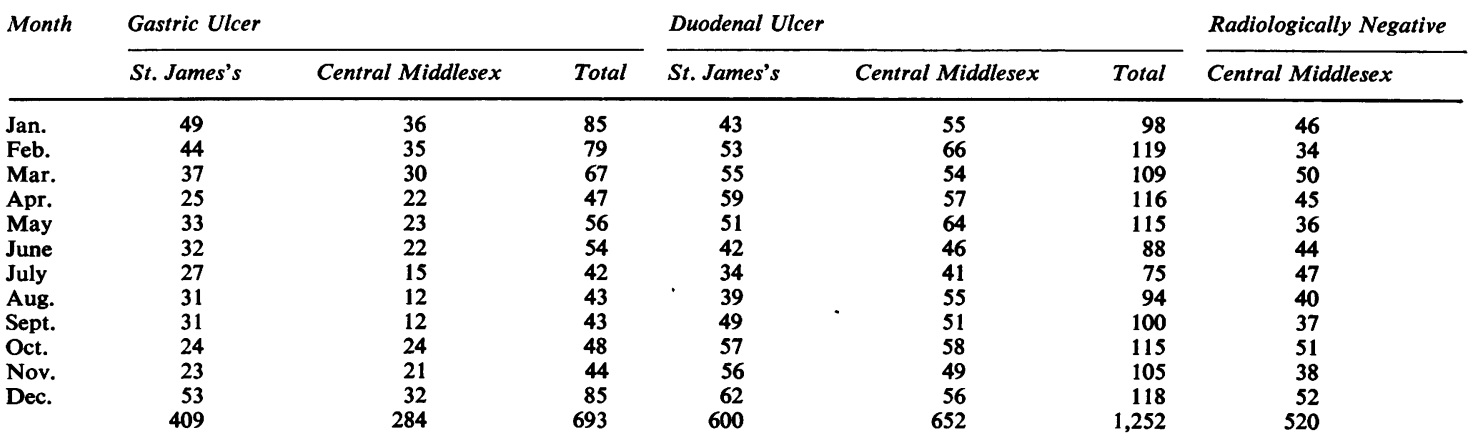

Gastric Ulcer

Total cases in summer months (April to September) $=285$

Total cases in winter months (October to March) $=408$

For the difference $x^{2}=21.83 \quad P<0.001$

$$
\mathbf{N}=1
$$

Duodenal Ulcer

Total cases in summer months $=\mathbf{5 8 8}$

Total cases in winter months $=664$

For the difference $\chi^{2}=4.32 \quad 0.05>P>0.02$

$$
\mathbf{N}=1
$$

Radiologically Negative

Total cases in summer months $=249$

Total cases in winter months $=271$

For the difference $\chi^{2}=0.93 \quad 0.5>P>0.3$

month. It is clear that there is a significant increase in admissions for bleeding ulcer during the winter months October to March compared with the summer months April to September. This variation is more marked for gastric than for duodenal ulceration. There is, however, no significant variation in cases of radiologically negative bleeding, albeit in a more limited series.

The results within the ulcer groups at the two hospitals are comparable except for a steep rise in admissions for gastric ulcer at St. James's Hospital in December (but not particularly at Christmas). The reason for this is unknown. There is also a variation in the duodenal : gastric ulcer ratio at the two hospitals; this may be due to differences in social structure of the populations served by each hospital, but is quite large, being $2: 1$ at the Central Middlesex Hospital and 3: 2 at St. James's Hospital.

Table II shows the compounded results for chronic ulcer cases at the two hospitals when divided into 'hot' and 'cold' months as explained.

For duodenal ulcer the greater incidence of bleeding is found in the 'hot' months but this difference does not reach levels of statistical significance. For gastric ulcer the difference is in favour of the 'cold' months but again it does not reach levels of significance although it is much closer to doing so.
It should be noted that this difference only occurs at one of the hospitals. It should also be noted that the temperature difference between 'hot' and 'cold' months at the same time of year is much less than that from summer to winter.

\section{DISCUSSION}

The present study clearly shows that there is an increased liability to haemorrhage from gastric and duodenal ulcers in the winter months. The results confirm those of Breen and Grace (1962) and Boles and Westerman (1954) recorded for duodenal ulceration in New York and Philadelphia. When one considers that in the present survey the difference is more marked for gastric ulceration it is surprising that it has not been reported before. The results obtained for radiologically negative cases do not, however, seem to follow the same trend and fail to reveal any variation at all.

The cause of the variation for bleeding ulcer is obscure. Table II certainly shows no inverse correlation with temperature for duodenal ulcer. For gastric ulcer such difference as is apparent is confined to one hospital; the compounded results for the two hospitals do not reach the 1 in 20 level of significance. This may be because the temperature difference 
TABLE IIa

INCIDENCE OF ADMISSIONS FOR ULCER HAEMORRHAGE 1952-61 DIVIDED MONTH BY MONTH AND INTO 'HOT' AND 'COLD' MONTHS

\begin{tabular}{|c|c|c|c|c|c|c|}
\hline \multirow[t]{2}{*}{ Month } & \multicolumn{2}{|l|}{ Gastric Ulcer } & \multicolumn{2}{|c|}{ Average Temperature $\left({ }^{\circ} \mathrm{F} .\right)^{1}$} & \multicolumn{2}{|c|}{ Duodenal Ulcer } \\
\hline & Hot Months & Cold Months & Hot Months & Cold Months & Hot Months & Cold Months \\
\hline Jan. & 38 & 47 & $39 \cdot 8$ & $36 \cdot 7$ & 57 & 41 \\
\hline Feb. & 41 & 38 & $40 \cdot 2$ & $34 \cdot 8$ & 66 & 53 \\
\hline Mar. & 21 & 46 & $43 \cdot 6$ & $38 \cdot 0$ & 53 & 56 \\
\hline Apr. & 20 & 27 & $45 \cdot 8$ & $41 \cdot 8$ & 54 & 62 \\
\hline May & 36 & 20 & $50 \cdot 6$ & $47 \cdot 6$ & 60 & 55 \\
\hline June & 25 & 29 & $55 \cdot 4$ & $52 \cdot 8$ & 39 & 49 \\
\hline July & 18 & 24 & $59 \cdot 0$ & $56 \cdot 4$ & 34 & 41 \\
\hline Aug. & 18 & 25 & $58 \cdot 8$ & 55.8 & 50 & 44 \\
\hline Sept. & 16 & 27 & $56 \cdot 0$ & $52 \cdot 2$ & 50 & 50 \\
\hline Oct. & 27 & 21 & $51 \cdot 0$ & $47 \cdot 8$ & 68 & 47 \\
\hline Nov. & 21 & 23 & $45 \cdot 4$ & $42 \cdot 0$ & 50 & 55 \\
\hline Dec. & 40 & 45 & 43.6 & $39 \cdot 2$ & 67 & 51 \\
\hline & 321 & 372 & & & 648 & 604 \\
\hline
\end{tabular}

Gastric Ulcer

For difference between 'hot' months and 'cold' months $x^{2}=3.46 \quad 0.10>\mathrm{P}>0.05$

Duodenal Ulcer

For difference between 'hot' months and 'cold' months $\chi^{2}=1.55 \quad 0.30>P>0.20$

$$
\begin{aligned}
& \mathbf{N}=1 \\
& \chi^{2}=1.55 \\
& \mathrm{~N}=1
\end{aligned}
$$

TABLE IIb

VARIATION IN TEMPERATURE RESULTS BETWEEN THE TWO HOSPITALS

\begin{tabular}{lccccc} 
& \multicolumn{2}{c}{ Gastric Ulcer } & & \multicolumn{2}{c}{ Duodenal Ulcer } \\
\cline { 2 - 3 } & St. James's & Central Middlesex & & St. James's & Central Middlesex \\
\hline Hot months & 181 & 140 & 306 & 342 \\
Cold months & 228 & 144 & 294 & 310
\end{tabular}

'Each temperature figure is the average of the five readings for the mean minimum temperature in each month.

between 'hot' months and 'cold' months at the same time of year is too small to show any significant variation.

Since the results for gastric ulcer, duodenal ulcer, and radiologically negative cases all differ, it is unlikely that they can be explained by a generalized bleeding tendency in the winter such as could have been ascribed to subclinical vitamin $\mathrm{C}$ deficiency. Again it might be suggested that intake of salicylate drugs increases in the winter and this could have caused an increase in the haemorrhage rate. If this were so then the radiologically negative group should show the greatest variation, for it should include the acute erosions which are said to be particularly associated with damage due to aspirin (Alvarez and Summerskill, 1958).

A decrease in the population at risk, caused by holidaying in the summer, should have affected the various groups more equally, so this hypothesis does not stand up to examination.

The same seasonal periodicity has been noted for perforated peptic ulcer, predominantly duodenal ulcer (Jamieson, 1947), and might well be found for exacerbations of ulcer pain. It may be that there is an association between respiratory disease and compli- cations of ulcers which could explain the seasonal variation, but this remains to be proved; indeed some evidence does exist to the contrary (Allibone and Flint, 1958).

It is a pleasure to thank Dr. F. Avery Jones and Dr. Richard Doll of this Department, Dr. B. F. Swynnerton, consultant physician to St. James's Hospital, the Director of the Meteorological Office, London Weather Centre, and Miss Barbara White, Librarian to the Department of Gastroenterology, Central Middlesex Hospital, for their help.

\section{REFERENCES}

Allibone, A., and Flint, F. J. (1958). Bronchitis, aspirin, smoking, and other factors in the aetiology of peptic ulcer. Lancet, 2, 179-182.

Alvarez, A. S., and Summerskill, W. H. J. (1958). Gastrointestinal haemorrhage and salicylates. Ibid., 2, 920-925.

Baker, C. (1947). Bleeding peptic ulcer. Guy's Hosp. Rep., 96, 1-56.

Boles, R. S., and Westerman, M. P. (1954). Seasonal incidence and precipitating causes of hemorrhage from peptic ulcer. $J$. Amer. med. Ass., 156, 1379-1383.

Breen, F. J., and Grace, W. J. (1962). Bleeding peptic ulcer: seasonal variation. Amer. J. dig. Dis., 7, 727-732.

Christiansen, T. (1935). On massive hemorrhage in peptic ulcer. Acta med. scand., 84, 374-385.

Hinton, J. W. (1931). Bleeding gastric and duodenal ulcers. Ann. Surg., 93, 844-856.

Jamieson, R. A. (1947). Perforated peptic ulcer. Brit. med. J., 2, 289-291. 